\title{
O turismo comunitário como ferramenta de desenvolvimento local nos territórios quilombolas
}

\author{
The Community Tourism as a local development tool in the \\ Quilombolas territories
}

Rosijane Evangelista da Silva

\begin{abstract}
RESUMO
O artigo faz reflexão sobre a prática turística nos territórios quilombolas, buscando analisar o processo de inserção da comunidade de Filipa, Maranhão, no contexto do turismo comunitário. O estudo aborda questões referentes à territorialidade (ALMEIDA, 1989) das comunidades quilombolas. Contextualiza o turismo comunitário como modelo de atividade que favorece e determina a participação e gestão de pequenas comunidades no processo de gerenciamento dos atrativos, garantindo-Ihes autonomia e preservação cultural e ambiental de seus recursos turísticos. Oportunizando, dessa forma, que os benefícios gerados pela atividade contemplem as necessidades da comunidade. Partindo-se de uma pesquisa bibliográfica e de campo, alicerçada pela observação participante, conclui-se que o legado sociocultural da comunidade de Filipa pode contribuir para o desenvolvimento do local, por meio de um aproveitamento turístico balizado nos princípios do turismo comunitário.
\end{abstract}

PALAVRAS-CHAVE: Comunidades Quilombolas; Turismo Comunitário; Filipa; Desenvolvimento Local.

\section{ABSTRACT}

The article provides insights on the touristic practice in the quilombolas territories, and it seeks to analyze the process of insertion of Filipa community, Maranhao state, in the context of a community-based tourism. The study has an approach the issues about the territory (ALMEIDA, 1989) of quilombolas communities. It contextualizes the communitarian tourism as a model of activity which contemplates and defines the participation and management of small communities in the process of management of attractions, and these factors can assure autonomy, and cultural and environmental preservation of their tourism resources. And, this way it maximizes the benefits originated in the activity itself can contemplate the needs of the community. Based on the literature review and field work, supported by participant observation, the conclusion is that the social and cultural heritage of Filipa Community can contribute to local development by a tourism optimization guided by community-based tourism principles.

KEYWORDS: Quilombolas Communities, Community-based Tourism, Filipa, Local Development. 


\section{Introdução}

O turismo tem sido qualificado como força significativa na geração de oportunidades de trabalho e renda em escalas locais e regionais (TRIGO, 1998). Nesse contexto, é possível visualizar em todo mundo experiências direcionadas para aproximar as comunidades locais dos benefícios gerados pela atividade turística.

O grande desafio dessas experiências é elaborar um modelo de turismo mais justo e equitativo, que considere as dimensões sociais, culturais, ambientais e econômicas que regem a vida social e insira a comunidade local no centro do planejamento, da implementação e do monitoramento do processo turístico, possibilitando a divisão equilibrada dos seus benefícios.

Muitas comunidades apontam para a necessidade emergente de estudos e estratégias que proporcionem sua inserção no contexto das rápidas transformações socioeconômicas que vêm ocorrendo. Assim, seguem buscando padrões de desenvolvimento que lhes permitam conciliar o crescimento econômico, equidade social e a preservação dos patrimônios socioculturais que as compõem. São exemplos dessa dinâmica as comunidades quilombolas, detentoras de formas de reprodução cultural diferenciadas, que enfrentam uma série de desafios na tentativa de garantirem a continuidade histórica de sua identidade e de seu patrimônio.

A Associação Brasileira de Antropologia- ABA define comunidade quilombola como toda comunidade negra rural que agrupe descendentes de escravos vivendo da cultura de subsistência e onde as manifestações culturais têm forte vínculo com o passado (ABA, 1994). Tal conceito designa a situação dos segmentos negro em diferentes regiões e contextos, sendo utilizado para caracterizar um legado cultural e material que oferece a esses grupos uma referência presencial no sentido de ser e pertencer a um lugar e a um grupo específico.

O Estado do Maranhão recebeu no período colonial, um grande contingente de escravos, fato muito presente na formação da identidade e da diversidade cultural do estado e no grande número de comunidades rurais remanescente de quilombos ali encontrados.

Essas comunidades buscam o autorreconhecimento identitário e a afirmação sociocultural, questões que se agregam aos problemas socioeconômicos resultantes do seu isolamento geográfico do processo de formação histórico do país. As comunidades tradicionais têm papel determinante na construção de um padrão de desenvolvimento que atenda suas necessidades e colabore na manutenção do meio onde estão inseridas, reforçando sua ligação com 0 território e com as paisagens culturais que compõem o meio ambiente. A busca por atividades alternativas, que visem à preservação cultural e ambiental das áreas onde vivem essas comunidades e que promovam o seu desenvolvimento em escala humana é um desafio continuo para esses grupos.

Dentre as alternativas sustentáveis para responder às exigências das comunidades tradicionais surge a atividade turística especialmente nos 
segmentos que promovem a cultura e a natureza e valorizem a autonomia das comunidades como é o caso do turismo comunitário. A forma de organização comunitária, a cultura e o etnoconhecimento das comunidades tradicionais em interação com o meio ambiente onde se reproduzem configuram um espaço imaginário de curiosidade com forte apelo de atração de visitantes.

Essa atividade, no entanto, muitas vezes é desenvolvida sem preconizar um planejamento sistemático capaz de minimizar os impactos negativos e potencializar os benefícios contidos em seu conceito. Ao mesmo tempo, as necessidades comunitárias, a relação com o ambiente natural e o legado cultural das comunidades não são observadas no âmbito dos interesses da atividade turística.

Este estudo investigou a atividade turística em implantação na comunidade quilombola de Filipa, a percepção dos moradores sobre o turismo e os aspectos culturais comunitários, base de sua organização e fator de influencia na determinação dos caminhos que buscam traçar. Localizada no município de Itapecuru, distante $120 \mathrm{~km}$ de São Luís, capital do Maranhão, com acesso pela BR 135, em área de 428 hectares, abriga 48 famílias, descendentes de mesmo tronco familiar. Nesta investigação, o olhar do pesquisador recorreu à pesquisa qualitativa e ao método etnográfico por acreditar ser o mais viável no alcance do atendimento dos objetivos a que se propõe este estudo. A pesquisa de campo usou como instrumentos metodológicos a observação participante, entrevistas semi estruturadas e diário de campo.

A observação participante se consolidou em oito visita a comunidade, realizadas no período de março de 2009 a fevereiro de 2010. As visitas aconteceram sem seguir um cronograma especifico determinadas pela adequação a atividades especificas da comunidade como, por exemplo, reunião da associação comunitária. Algumas visitas foram planejadas para acontecer para se adequar a uma festa religiosa, uma apresentação do tambor de crioula de Filipa ou ao período da colheita e partilha da produção comunitária. As entrevistas semi estruturadas foram sistematizadas por roteiros orientativos. Os roteiros foram elaborados com base nos objetivos propostos como metas a serem delineadas pela pesquisa, auxiliados pelos dados levantados em campo nas observações preliminares. As entrevistas se desenvolveram a partir de quatro diferentes roteiros, embora muitas vezes os relatos, acabaram por orientar a inclusão ou exclusão de questões percebidas pela prática do campo.

As entrevistas foram direcionadas, num primeiro momento para pessoas chaves da comunidade, indicadas ou eleitas como desempenhando papeis de lideranças pelos membros da própria comunidade. Algumas dessas lideranças são formais como, o presidente da associação dos moradores, presidente da associação de jovens produtores de Filipa, membros da diretoria do Sindicato dos Trabalhadores Rurais do município e conselheiros do conselho diretivo da ACONERUQ (Associação das Comunidades Rurais Remanescente de Quilombos), outras são lideranças legitimadas pelas experiências comunitárias e pelo papel desempenhados na consolidação dos laços afetivos e das sinergias, lutas, e conquistas da comunidade, como D. Nielza, professora e catequista de 
Filipa que centraliza em sua figura simples a confiança, o respeito e as expectativas dos demais membros da comunidade.

\title{
Quilombos no Brasil e no Maranhão: trajetória histórica
}

A expressão quilombo, de origem banto (Kilombo), significa acampamento ou fortaleza, estando presente na historiografia brasileira desde a primeira metade do século XVIII, usada pelos portugueses para designar as povoações ou agrupamentos constituídos por escravos fugidos dos cativeiros:

\begin{abstract}
Onde houve escravidão, houve resistência. E de vários tipos. Mesmo sob ameaça de chicote, o escravo negociava espaços de autonomia, fazia corpo mole no trabalho, quebrava ferramentas, incendiava plantações, agredia senhores e feitores, rebelava se individual e coletivamente. Houve um tipo de resistência que poderíamos considerar a mais típica da escravidão [...] trata-se das fugas e formação de grupos de escravos fugidos [...] essa fuga aconteceu nas Américas e tinha nomes diferentes: na América espanhola: Palenques, Cumbes; na inglesa, Maroons; na francesa, grand Marronage e petit Marronage [...]; no Brasil, Quilombos e Mocambos e seus membros: Quilombolas, Calhambolas ou Mocambeiros (REIS, 1996, p.47).
\end{abstract}

Os quilombos marcaram praticamente todo o território como sinal de protesto às condições desumanas e degradantes a que estavam sujeitos os escravos. Estes se constituíram em territórios étnicos de resistência, como alternativa de organização sócio-político-espacial às diversas formas de exploração do trabalho negro e escravo.

Os territórios das comunidades negras, portanto, têm suas origens nos quilombos ou mocambos formados, sobretudo, pelos escravos que se rebelavam contra a escravidão. Mas, também, algumas comunidades se formaram através de doações de terras realizadas a partir da desagregação da lavoura de monoculturas, como a cana-de-açúcar e o algodão; da compra de terras pelos próprios escravos, possibilitados pela desestruturação do sistema escravista; bem como de terras que foram conquistadas pelos negros pela prestação de serviço de guerra, lutando contra insurreições ao lado de tropas oficiais.

Segundo Almeida (2008), há, também, a indicação de que representam uma territorialidade derivada da propriedade detida em mãos de ordens religiosas, da doação de terras para santos e do recebimento de terras em troca de serviços religiosos prestados a senhores de escravos por negros (as) sacerdotes de cultos religiosos afro-brasileiros. Assim, a concepção de que os quilombos seriam constituídos somente a partir de fugas, processos insurrecionais ou de grupos isolados apresenta-se equivocada.

A identificação de quilombos no meio rural do Brasil contemporâneo fez rever a conceituação tradicional como fuga e resistência escravista. Esta diversidade das formas de constituição das terras de quilombos 
proporcionou a retomada de discussões e pesquisas sobre o conceito de quilombo, cujo teor se revelou no momento em que se iniciaram as tentativas de titulação dessas terras amparadas pelo Artigo 68 das Disposições Transitórias da Constituição de 1988.

Dentro de uma visão ampliada que considera as diversas origens e histórias destes grupos, uma denominação para estes agrupamentos identificados como remanescentes de quilombo seria a de terras de preto, atribuída, por exemplo, aos remanescentes existentes no Maranhão e utilizada por vários autores (ALMEIDA, 1989, LEITE 2000) para descrever as comunidades negras, uma denominação que enfatiza a sua condição de coletividades camponesas e identifica uma expressão nativa e não uma denominação historicamente imposta e restritiva. A expressão terras de preto é usada pelos moradores de comunidades negras rurais para definir seus territórios. Funciona como uma nomenclatura de origem nativa em contraposição à outras expressões utilizadas e as vezes impostas por pessoas externas às comunidades. Conforme veremos adiante a expressão engloba um sentido mais abrangente de território e identificação (ALMEIDA, 1989).

Contemporaneamente, a expressão quilombo não se refere a resíduos ou resquícios arqueológicos de ocupação temporal ou de comprovação biológica. Bem como não se trata de grupos isolados ou de uma população estritamente homogênea. Da mesma forma, nem sempre foram constituídos a partir de movimentos insurrecionais ou rebelados, mas, principalmente, consistem em grupos que desenvolveram práticas cotidianas de resistência na manutenção e reprodução de seus modos de vida característicos e na consolidação de um território próprio (ABA, 1994).

No relativo à territorialidade desses grupos, a ocupação da terra não é feita em termos de lotes individuais, predominando seu uso comum. A utilização dessas áreas obedece à sazonalização das atividades, sejam agrícolas, extrativistas ou outras, caracterizando diferentes formas de uso e ocupação dos elementos essenciais ao ecossistema, que estabelecem por base laços de parentesco, vizinhança e compadrio, assentados em relações de solidariedade e reciprocidade.

A vinculação das comunidades ao território caracteriza-se como fator fundamental, afinal, além de ser condição de sobrevivência física para os grupos, a terra constitui-se instrumento relevante à afirmação da identidade da comunidade, para a manutenção e continuidade de suas tradições.

Para caracterizar essa relação, Almeida (2008, p.25) faz uso da noção de territorialidade específica como resultado "[...] dos diferentes processos sociais de territorialização, delimitando dinamicamente terras de pertencimento coletivo que convergem para um território". Sob esse olhar, os quilombos podem ser percebidos como territórios específicos dentro de um Estado pluriétnico. As especificidades de cada grupo referem-se ao processo de construção política do território, relacionado com suas manifestações socioculturais, modos de produção e manejo ambiental em relação à terra tradicionalmente ocupada, que é o meio pelo qual as condutas de territorialidade desenvolvem-se. 
A noção de território para as comunidades quilombolas é baseada no trabalho familiar, isto é, uma unidade familiar é também uma unidade econômica que se circunscreve num território, regida por normas consuetudinárias de trabalho e convivência social, reconhecidas e respeitadas pelos moradores da área e pelos vizinhos próximos. Assim, o regime de uso comum dos recursos naturais "dotou de longevidade essas terras, consolidado-as enquanto território étnico, e tornando-se fator fundamental de identidade desses camponeses agrupados" (PROJETO VIDA DE NEGRO, 2002, p.87).

No que tange à apropriação comunal das terras, Almeida destaca que

\begin{abstract}
Elas designam situações na quais o controle dos recursos básicos não é exercido livre e individualmente por um determinado grupo doméstico de pequenos produtores diretos ou por um de seus membros. Tal controle se dá através de normas específicas instituídas para além do código legal vigente e acatadas, de maneira consensual, nos meandros das relações sociais estabelecidas entre vários grupos familiares, que compõem uma unidade social (ALMEIDA, 2005, p.133).
\end{abstract}

Desse modo, o regime de uso comum favorece a consolidação do território étnico e representa fator fundamental de identidade cultural e coesão social. Barreto Filho (2006, p.112) se refere à apropriação comunal das terras de comunidades negras como forma de sinal de resistência fundamentada no território. Para o autor,

\begin{abstract}
O controle sobre a terra se faz grupalmente sendo exercido pela coletividade que define sua territorialidade com base em limites étnicos fundados na afiliação por parentesco, coparticipação de valores, de práticas culturais e principalmente da circunstância especifica de solidariedade e reciprocidade desenvolvida no enfrentamento da situação de alteridade proposta pelos brancos (BARRETO FILHO, 2006, p.112).
\end{abstract}

Assim, a proteção e afirmação dos direitos das comunidades remanescentes de quilombos passam necessariamente pela regularização fundiária e pelo reconhecimento dos territórios tradicionalmente ocupados. O território é o elemento de construção da identidade étnica, que representa o ponto mais importante da estrutura social.

Os territórios quilombolas resultam de um tipo particular de percepção e apropriação do espaço, sendo constituídos por formas de organização social, comunicação grupal e laços de solidariedade comunitária específicos, ligando os indivíduos a um passado ou origem étnica comum. Apresentam-se como verdadeiros sítios simbólicos de pertencimento, reveladores de vivências, crenças, ritos, rituais, celebrações, costumes e estilos de vida dessas comunidades, "os sítios apresentam, com efeito, esta extensão imbricada que os tornam, apesar de seu caráter único, 
entidades plurais que vivem da diversidade circundante" (ZAOUAL, 2006, p.37).

\title{
Os quilombos maranhenses: sinais da resistência
}

No Maranhão, conforme o levantamento realizado por Pesquisa da Universidade de Brasília-UNB (NAVARRO, 2005) realizada pelo Centro de Geografia e Cartografia Aplicada (CIGA), identifica-se a existência de cerca de 640 comunidades remanescentes de quilombos no Estado. Levantamentos anteriores empreendidos Projeto Vida de Negro, na década de 1980 já haviam mapeado a situação e identificado a forte presença dessas comunidades portadoras de referências étnicas similares.

Hoje, no estado, é marcante a presença de um campesinato com forte afro-ascendência ocupando as chamadas "terras de preto", denominadas por Almeida como "domínios que foram entregues, doados ou adquiridos, com ou sem formalização, por ocasião da decadência das grandes fazendas monocultoras" (ALMEIDA, 1989, p.163). Os descendentes de tais famílias "permanecem nessas terras há várias gerações sem proceder ao formal de partilha e sem delas se apoderarem individualmente" (Ibidem, p.164). Esses locais foram ocupados pela população negra que sobreviveu no período pós-Abolição e serviu como base para a formação de comunidades que ainda residem na terra.

As "terras de preto", entretanto, não se restringem apenas aos domínios acima citados, conforme Almeida (1994, p.179-180):

\begin{abstract}
A expressão alcança também aqueles domínios ou extensões correspondentes a antigos quilombos e áreas de alforriados nas cercanias de antigos núcleos de mineração, que permaneceram em isolamento relativo, mantendo regras de uma concepção de direito, que orientavam uma apropriação comum dos recursos. Há ainda aquelas que foram conquistadas por prestação de serviços guerreiros ao Estado, notadamente na guerra da Balaiada (1838-1841).
\end{abstract}

Conforme estimativas disponíveis referentes às chamadas "terras de preto", só no estado do Maranhão estas "ultrapassam a um milhão de hectares" (ALMEIDA, 1994, p.181). As terras de preto, configuram - se na atualidade em povoados que produzem com o sistema de uso comum da terra e constituem-se numa base fixa considerada comum, essencial e inalienável, onde o convívio social é norteado por valores, e os laços de consanguinidade e compadrio têm relevância e são observados e cumpridos. De acordo com descrição de Almeida (2008, p.157) "as formalidades não recaem necessariamente sobre os indivíduos, sendo que a família se põe acima de muitas exigências sociais".

Conforme, Andrade (2006), ainda que o Maranhão seja um estado periférico sob muitos pontos de vista, no tocante as discussões e articulação das questões quilombolas, na produção de conhecimento e no subsídio para políticas públicas, o estado tem desempenhado desde a década de 1980 um papel de centro. Assim o Maranhão tem um papel pioneiro nas 
lutas por reconhecimento étnico e valorização territorial das comunidades quilombolas brasileiras.

O trabalho do Centro de Cultura Negra do Maranhão - CCN e da Sociedade Maranhense de Defesa dos Direitos Humanos - SMDH, com a criação do Projeto Vida de Negro - PVN possibilitou o levantamento, o mapeamento e a mobilização das comunidades em torno de um objetivo comum, possibilitando as comunidades quilombolas maranhenses chamar atenção e participar ativamente das discussões que precederam a Assembleia Constituinte de 1988.

A Associação das Comunidades Negras Rurais do Maranhão ACONERUQ fundada em novembro de 1997, em substituição à Coordenação Estadual Provisória dos Quilombos, criada em 1995, congrega 246 (duzentas e quarenta e seis) comunidades negras rurais, e se vincula à Coordenação Nacional de Articulação das Comunidades Negras Rurais Quilombolas -CONAQ.

$\mathrm{Na}$ década de 1990, ganhou ênfase no cenário nacional a necessidade de debates sobre as bases definidoras do termo quilombo. $O$ processo de discussão contou com a participação de antropólogos, movimento negro e lideranças das comunidades quilombolas. O conceito foi ressignificado e passou a ser utilizado pelas lideranças e intelectuais envolvidos com as comunidades. Esta prática foi verificada por ocasião do "IV Encontro das Comunidades Negras Rurais do Maranhão", realizado na cidade de São Luís, em abril de 1995. O encontro teve então como tema "Os Quilombos contemporâneos e a luta pela Cidadania". Conforme Fabiani (2005) essa foi a primeira vez que no âmbito público as lideranças negras rurais maranhenses usaram como forma de apropriação a expressão quilombos contemporâneos.

\section{Turismo comunitário e desenvolvimento local}

Estudos realizados no Brasil e no mundo, comprovam que o turismo quando desenvolvido seguindo os padrões do mercado e ao modelo de grandes complexos hoteleiros, não proporciona benefícios efetivos para a comunidade do entorno. Como destaca Hatton: "The Influence of this type de resort on the community is minimal. In effect, there are tourists, but no turism industry ${ }^{1}$.

É nesse contexto que o turismo comunitário busca se construir como um contraponto e uma alternativa ao turismo especulativo e massivo dos grandes capitais. Apoiado por uma oferta de serviços e infraestrutura mais simples, porém não menos qualificada, o turismo comunitário se desenvolve buscando valorizar os ambientes naturais e a cultura local. Configurando-se assim como uma nova perspectiva de visitação e de hospitalidade. Trata-se de uma nova concepção, da formulação de uma proposta turística que internalize a variável local e as identidades envolvidas.

Quando se fala em turismo comunitário ou de base comunitária, estamos nos referindo àquele turismo construído pela comunidade e para a comunidade, onde os atores sociais comunitários não apenas participam, mas têm controle efetivo nas decisões relativas ao turismo na localidade. Ou 
seja, é um turismo no qual, usando a expressão de Krippendorf (2000) o "nativo mudo" adquire expressão e exerce um papel ativo.

Esse turismo tem como subsídio o respeito às heranças culturais e tradições locais, podendo servir de veículo para revigorá-las e por vezes resgatá-las. Possibilita o estabelecimento de relações centradas no diálogo e na interação entre visitantes e visitados, onde nem anfitriões são submissos aos turistas, nem os turistas fazem dos hospedeiros objetos de instrumentalização consumista (BUSRZTYN; BARTHOLO; DELAMARO, 2009), favorecendo a troca de experiências e o diálogo igualitário.

O turismo comunitário traz em sua gênese a complexidade peculiar que caracteriza o fenômeno turístico como um todo. A abordagem conceitual dessa proposta de turismo é referenciada, entre outros fatores balizadores, principalmente a partir das experiências em desenvolvimento pelo país. Apresentar um marco conceitual para o turismo comunitário constitui-se, portanto um desafio, sobretudo considerando a diversidade de contextos, histórias, lugares e personagens que fazem de cada uma das iniciativas comunitárias únicas.

Para o WWF-Internacional (2001), turismo comunitário é,

Aquele onde as sociedades locais possuem o controle efetivo sobre seu território, desenvolvimento e gestão. E por meio do envolvimento participativo desde o início, projetos de turismo devem proporcionar a maior parte de seus benefícios para as comunidades locais.

As definições apresentam ideias tais como a conservação ambiental, a valorização cultural, a participação comunitária e a geração de benefícios para as comunidades receptoras. Nas abordagens conceituais brasileiras expostas a seguir, são adicionadas as noções de empreendimentos comunitários e intercâmbio intercultural:

Turismo comunitário é toda forma de organização empresarial sustentada na propriedade do território e da autogestão dos recursos comunitários e particulares com práticas democráticas e solidárias no trabalho e na distribuição dos benefícios gerados através da prestação de serviços visando o encontro cultural com os visitantes (TURISOL ${ }^{2}$, 2008).

O turismo de base comunitária é aquele no qual as populações locais possuem o controle efetivo sobre o seu desenvolvimento e gestão e está baseado na gestão comunitária ou familiar das infraestruturas e serviços turísticos, no respeito ao meio ambiente, na valorização da cultura local e na economia solidária (TUCUM $\left.{ }^{3}, 2008\right)$.

É baseado nesses pilares que o turismo comunitário constrói sua fundamentação e emerge com maior alcance e visibilidade para discussões 
e experiências que buscam consolidar um novo modo de pensar o turismo. O exercício do turismo comunitário amplia-se e começa a abrir espaço no contexto do turismo global onde se destaca o local como lugar de desenvolvimento. A inserção dessa prática turística já evidencia implicações para a configuração de políticas públicas de turismo em diversos países.

Em sua proposta, o turismo comunitário envolve a comunidade no projeto desde as discussões iniciais de sua concepção até o objetivo final, garantindo a distribuição mais igualitária dos lucros alcançados (CORIOLANO, 2009). Os moradores são envolvidos e participam ativamente na construção de estratégias condizentes com a realidade e vocação do lugar, e com a estruturação de pequenos empreendimentos e atividades pensados para atender a uma demanda específica de visitantes. Desse modo, o turismo comunitário emerge para as comunidades como um processo de descoberta, quando as comunidades buscam o que querem e como querem e podem fazer para contribuir para o desenvolvimento das pessoas e do local (CORIOLANO, 2009).

Esse tipo de turismo tem como características a elaboração de planejamentos descentralizados e associativos buscando garantir a participação de todos. Assume lutas já iniciadas pela regulamentação das terras comunitárias e pela garantia dos direitos das pessoas do local. Trabalha pela regulamentação de unidades de conservação e na organização de comitês para gestão ambiental e cultural de seus espaços, com planos de manejo e conservação compatíveis com o turismo (CORIOLANO 2009).

O turismo comunitário é realizado como um projeto de desenvolvimento sustentável a partir da própria comunidade. Sua atuação estimula o fortalecimento dos laços sociais e o sentido coletivo de vida em sociedade e por este caminho promove a qualidade de vida, o sentido de inclusão, à valorização da cultura e do sentimento de pertencimento. Esse tipo de turismo representa uma perspectiva de desenvolvimento que transcende o crescimento econômico e traduz uma interpretação local do turismo. As iniciativas comunitárias devem ser expressão das necessidades locais, e empreendidas de modo a despertar o protagonismo social e o desenvolvimento local, condições essenciais para a realização plena da atividade turística em bases comunitária.

Segundo Buarque (1994), desenvolvimento local é um processo endógeno verificado em pequenas regiões e agrupamentos humanos, sendo capaz de alavancar o crescimento econômico e a consequente melhoria da qualidade de vida da população. Provoca uma transparente transformação nas bases econômicas e na organização social em nível local, partindo da sinergia entre os atores, utilizando as suas capacidades e potencialidades específicas.

Beni (2007) destaca o desenvolvimento endógeno como uma estratégia de ação, traçada para atender as demandas das comunidades locais através da participação da comunidade envolvida, ou seja, é a capacidade que as comunidades locais possuem de liderar seu próprio processo de desenvolvimento através da mobilização de seu potencial e recursos internos. 
O desenvolvimento local associa-se a iniciativas inovadoras e mobilizadoras da coletividade, evidenciando as potencialidades locais nas condições dadas pelo contexto. Conforme afirma Haveri (1996, s/p), "As comunidades procuram utilizar suas características específicas e suas qualidades superiores e se especializar nos campos em que têm uma vantagem comparativa com relação às outras regiões".

As terras de Filipa hoje pertencem à comunidade. Esse sentimento de coletividade com relação a terra reforça os vínculos de união dos moradores, sendo expresso pelos mesmos nas falas e depoimentos, conforme expressa o Senhor Xavier Ferreira, morador e líder comunitário em Filipa: "É de todos, não sendo de ninguém."

As fontes utilizadas para contar a história de Filipa são quase todas orais, coletadas nas conversas, parte da memória de seus moradores mais antigos, portanto, não há como precisar datas e números. Os fatos, porém, repassados e guardados através das gerações são perpetuados como representantes do universo simbólico da construção da identidade de Filipa. Existem algumas fontes documentais como papéis de igreja, cartório, documentos de titulação da terra em fase de legitimação pelo Instituto Nacional de Terras e Colonização - INCRA, também documentos da associação comunitária, são, contudo mais recentes.

A história da formação da comunidade, de acordo com os moradores mais velhos, data de bem mais de cem anos. Começou com os avós em um tempo em que a terra não tinha dono, que ser dono era morar e produzir na terra. Contam que tudo começou com a chegada de uma escrava chamada Filipa Ferreira Vianna, em um lugar chamado Barriguda. Esta escrava Filipa, gostou do lugar e ali se estabeleceu com o filho. Depois de algum tempo, supostamente após sua morte o lugarejo passou a se chamar morro de Filipa em sua homenagem e finalmente somente Filipa. Os descendentes da escrava Filipa, reunidos em grupo, falam com orgulho de sua origem, esse orgulho está presente na fala de D. Nielza Ferreira Vianna, bisneta de Filipa: "A Filipa, ela veio de uma escravidão. Ela foi descendente de escravos."

Filipa partilha uma descendência em comum, em que quase todos os moradores são parentes, com exceção daqueles poucos que se incorporaram à comunidade pelo casamento, conforme nos conta a Senhora Donata, ela própria agregada à comunidade pelo casamento: "Com certeza aqui é uma família só. A maioria do pessoal que mora aqui na Filipa é filho daqui, nascido e criado aqui, é difícil ter um de fora"4.

Filipa viu sua realidade difícil, isolada e excluída começar a mudar a partir de um trabalho de conscientização e resgate da identidade cultural da comunidade, promovido pelo Centro de Cultura Negra do Maranhão - CCN. Por sentirem-se discriminados por causa da cor da pele, os moradores não se sentiam fortes, não iam atrás de informações que pudessem resultar em melhorias para a vida comunitária, isolavam-se cada vez mais no seu interior. As tradições estavam sendo aos poucos abandonadas, ou trocadas por coisas mais modernas, os jovens já não dançavam, nem tocavam o tambor-de-crioula. O resgate do orgulho em ser negro e a valorização do espólio herdado dos ancestrais escravos foi fundamental para a autoafirmação da comunidade, abrindo caminhos para o desenvolvimento. 
A cultura é apreendida nas falas da comunidade como o ponto de resgate do orgulho e do pertencimento e o $\mathrm{CCN}$ foi um impulsionador do processo de melhoria de vida em Filipa:

Olha eu diria que o primeiro ponto foi a cultura, a comunidade se uniu, porque nós somos negros, mas não tínhamos orgulho, não tinha tipo, uma identidade. Depois que eu tive a oportunidade de participar de dois encontros em São Luís, a gente fez um convite para esse pessoal vir até aqui, aí eles vieram, e agente começou a se unir, se organizar, e eles começaram vindo e com a vinda deles, é que hoje em Filipa está vindo, vocês, já veio o pessoal dos Estados Unidos, [...] está vindo muita gente, primeiro começou com o Movimento Negro de São Luís, que abriu as portas para Filipa (BELFORT, 2009).

Eu tenho muito orgulho da minha cor, sinceramente (VIANNA, 2009).

\section{Filipa hoje}

A construção da autoestima da comunidade foi determinante para a organização em busca das melhorias. Atualmente as pessoas de Filipa afirmam com orgulho e dignidade sua identidade. Essa realidade é expressa no ritmo fortemente marcado do tambor-de-crioula, herdado dos pais e avós e que constitui alegria, prazer, lazer e perpetua a cultura negra. O Tambor de Filipa também viveu um reflorescimento. Hoje as crianças aprendem a tocar, cantar e dançar com os mais velhos e o tambor é conhecido e prestigiado por toda a região. As pessoas da comunidade se expressam sobre o tambor assim: "O tambor lembra primeiramente dos antepassados, segundo é alegria. É a única diversão que a gente tem aqui." (VIANNA, 2009). Ou: "tambor é amor, é paixão, tradição" (BELFORT, 2009).

O tambor de crioula é elemento de unificação, de identidade, de força e união. As canções falam de fatos da vida cotidiana na comunidade, da história dos parentes e vizinhos, criando laços de reconhecimento que servem de ajuda para enfrentar as dificuldades da vida. Em Filipa, todos são católicos, não havendo manifestações das religiões afrodescendentes como tambor de mina, terecô, candomblé, e outros. Assim o tambor de crioula sintetiza a relação mais íntima com a descendência africana.

A festa de São Sebastião realizada em agosto é muito valorizada. Todos participam ativamente dos preparativos, as comunidades vizinhas são convidadas, bem como os parentes e amigos da capital e de lugares mais distantes. Tem novena, procissão e missa, leilão, baile e tem também tambor de crioula. O povo é fervoroso e dá o melhor de si para homenagear o padroeiro. Nesse período evidencia-se também a hospitalidade, o bem receber herdado dos pais e avós, que torna Filipa já conhecida entre as comunidades da região.

Baseados no prazer de compartilhar momentos, divertir, rezar e trabalhar juntos e nessa redescoberta da identidade cultural, organizaramse em Associação de Moradores e passaram a militar na luta por melhores condições de vida não apenas para si, mas para todas as comunidades 
negras do Maranhão. Em 1997, Filipa participou do V Encontro de comunidades negras, como sócio-fundadora da Associação das Comunidades Negras Rurais Quilombolas - ACONERUQ.

A partir da organização comunitária Filipa abriu caminhos para requerer junto a órgãos institucionais projetos que, a partir de uma perspectiva endógena, favorecem o desenvolvimento da comunidade. Buscou estabelecer laços identitários e o reconhecimento como comunidade quilombola, reforçou também os vínculos de união e respeito entre seus moradores, juntando esforços para otimizar os resultados dos projetos e passou a compor junto com outras comunidades a luta pelo reconhecimento de seu território.

Filipa tem viabilizado projetos através de órgãos estaduais de Fomento para instalação de infraestrutura física para comunidades rurais. Desse modo, a comunidade conseguiu viabilizar a energia elétrica e construção de estrada para o acesso à comunidade.

Participou de linhas de financiamento rural para desenvolver o cultivo de abacaxi e banana, viabilizou através de mecanismos estatais água tratada e encana e a implantação de uma pequena agroindústria de beneficiamento de farinha e arroz.

O potencial turístico de Filipa está baseado nos aspectos culturais e naturais da comunidade. Entre os aspectos culturais destaca-se o Tambor de Crioula, parte significativa do lazer e do imaginário cultural. Herança dos ancestrais o Tambor de Crioula em Filipa não precisa de motivo, nem de data especifica para ser brincado, basta a comunidade está reunida, o tambor é elemento do lazer comunitário que pode ser apresentado e ensinado aos turistas em qualquer época, sem comprometer o aspecto tradicional da brincadeira.

Outra festa tradicional em Filipa é o Festejo de São Sebastião, padroeiro local. O festejo harmoniza o religioso e o profano, pois além da parte ritual representada pela novena que precede a festa, da missa e da ladainha rezada em latim realizada na capela dedicada ao Santo localizada no centro do povoado.

Como atrativos naturais têm-se o rio Itapecuru, matas inexploradas propícias para a realização de trilhas, e belas paisagens verdes imersas no silêncio rural que favorecem o relaxamento e o descanso. Além do modo de vida local, suas práticas tradicionais de cultivo e sua ligação com os ciclos da natureza, seus conhecimentos da flora local, e os aspectos culturais da comunidade.

A introdução do turismo como mecanismo de desenvolvimento local chega a Filipa a partir de políticas públicas apresentadas por órgãos federais e estaduais de fomento ao desenvolvimento rural e às questões agrárias, como o INCRA, a Empresa Brasileira de Pesquisa Agropecuária EMPRAPA e o Serviço Nacional de Apoio a Micro e Pequena Empresa SEBRAE, entre outros, e em cujo portfólio de projetos apresenta o turismo sustentável como linha para sua atuação junto às comunidades rurais.

A atividade turística vem sendo reconhecida, no âmbito do governo federal, como atividade com grande potencial gerador de renda, 
configurando-se como parte de política de desenvolvimento e inclusão para comunidades e setores da sociedade. Por esse motivo, o turismo tem composto planos de ação de vários órgãos e apresentado, como eixo integrador, no caso do interesse deste estudo, da Política Nacional de Desenvolvimento Sustentável dos Povos e Comunidades Tradicionais PNPCT, estabelecida pelo governo federal em 2007, como política norteadora do desenvolvimento de comunidades tradicionais.

A comunidade não apresenta visitação nos moldes do mercado turístico, mas, atraídos pelas relações particulares estabelecidas pela comunidade e pelo resultado positivo de projetos agrícolas desenvolvidos, é frequente a presença de visitantes em Filipa. Frente a essa demanda, motivada por interesses nos processos produtivos e na organização comunitária, a atividade acontece em Filipa de forma espontânea. Não é possível caracterizar a comunidade como prestadora de serviços turísticos, não existe infraestrutura de receptivo e não há geração de receita advinda do turismo. A entrada de recursos financeiros obtida com a visitação turística é pequena e pontual e, quando ocorre, é direcionada para a Associação de Moradores, com vistas a atender necessidades coletivas. Os moradores se posicionam sobre a atividade assim:

A gente, às vezes, diz que não existe, mas existe, pois recebemos muito visitantes. Gente até do estrangeiro, Estados Unidos, Equador, França e de vários lugares do Brasil também: Pernambuco, Rio de janeiro, Rio Grande do Sul (VIANNA, 2009).

Aqui já veio gente que nós nem entendíamos o que falavam, precisava a Carla traduzir (BELFORT, 2009).

Os moradores apresentam uma percepção própria sobre o turismo e a forma como este deve chegar à comunidade. Nessa percepção a geração de renda aparece como um dos principais benefícios trazidos pelo turismo, porém concomitantemente a preocupação com os efeitos nocivos associados à violência, prostituição e a interferências no modo de vida de Filipa.

O turismo é bom, mas ele corre um risco pra comunidade. Eles vêm pra comunidade, a comunidade tem como receber! Mas agente acha que assim como pode ser bom, pode ser complicado (SANTOS, 2009).

Muita gente espalha sujeira pelo chão e tem muitas pessoas que não tem respeito pelos outros, não respeita as normas e nem as mulheres da comunidade (SANTOS, 2009).

O turismo traz a vantagem de aumentar o recurso, conhecer outras pessoas, levar nossa realidade pros outros (FERREIRA, 2009). 
Nas falas da comunidade, o turismo aparece como possibilidade de renda. Porém, questões como respeito aos moradores e ao modo de vida, conservação do território, valorização da cultura da identidade local, são expressões que ganham maior importância nas relações desenvolvidas com os visitantes, o que leva a crer que o interesse comunitário na atividade se focaliza numa perspectiva de valorização do legado sociocultural da localidade. Os moradores destacam como positiva a interação recíproca que estabelecem no contato com os visitantes. Descrevem os encontros numa perspectiva de valorização e reconhecimento de seu modo de vida, de sua luta por reconhecimento do seu território quilombola.

No arcabouço dos órgãos de fomento, a comunidade já participou de cursos, oficinas e sensibilização em preparação para o turismo, além de ter representação seminários que discutem o turismo e as consequências que a atividade pode gerar. Tiveram a oportunidade de conhecer as experiências de outras comunidades que já realizam turismo em seus territórios, como, por exemplo, a participação, em 2010, no primeiro Seminário Nacional de Turismo em Quilombos, realizado no quilombo paulista de Ivoporanduva e promovido pelo Ministério do Meio Ambiente, que gerou um documento orientativo para a elaboração de políticas públicas de turismo em territórios quilombolas.

Na percepção dos moradores de Filipa o desenvolvimento do turismo deve acontecer de forma planejada e continuada de modo a garantir os benefícios de sua efetivação, e não somente como estratégias impostas pelos órgãos externos ou porque outros estão fazendo, mas por avaliarem que será bom para a coletividade.

\section{Considerações finais}

O turismo tem sido apontado, como instrumento capaz de articular desenvolvimento econômico equilibrado, melhorias das perspectivas das populações e preservação ambiental e valorização cultural, dentro de um planejamento responsável. As práticas turísticas constituem um conjunto de bens e serviços que visa favorecer o desenvolvimento das comunidades locais.

Considerar as opiniões dos comunitários, seu conhecimento das áreas, experiências e sabedoria são determinantes para o êxito do turismo comunitário. Dar voz às pessoas da comunidade e considerar as subjetividades coletivas das populações locais no processo de construção de uma atividade turística responsável pode revelar-se construtivo para a atividade e para as comunidades.

Filipa é uma comunidade negra que permanentemente se constrói através dos laços materiais e imateriais das representações coletivas que estabelece em seu território ancestral. A interpretação do turismo comunitário como uma possibilidade para o etnodesenvolvimento local se dá não apenas em função de seu potencial para a geração de renda, mas também por estimular a autonomia, a valorização e o respeito ao modo de vida e a cultura de comunidades étnicas, como Filipa, caracterizando o papel social do turismo, conforme argumenta Irving (2008). A leitura compreendida a partir da ótica local considera ainda o turismo comunitário 
uma alternativa produtiva importante para as estratégias de manutenção do território quilombola de Filipa à medida que promove a autoestima e o orgulho do pertencimento dos moradores, bem como lhes proporciona a oportunidade de falar, ainda que não diretamente dos anseios e aspirações que permeiam seu cotidiano de lutas pela sobrevivência e por reconhecimento de suas singularidades, configurando-se assim uma forma de dar visibilidade aos problemas que enfrentam pela manutenção de seu modo de vida quilombola.

A prática do turismo, orientado pelos princípios do turismo comunitário, associado às potencialidades locais tem se construído como uma possibilidade para os moradores de Filipa. Possibilidade esta, relacionada à importância econômica da atividade, mas também à valorização da cultura tradicional, como novas percepções decorrentes da troca de experiência entre a população local e os turistas que visitam a área, com base no pressuposto de compromisso ético, respeito e engajamento da parte de quem pertence e de quem se agrega ao desenvolvimento local (IRVING,2008). No entanto, a comunidade também conhece as consequências indesejáveis que o turismo pode acarretar, e se prepara para avaliar os riscos.

\section{Referências bibliográficas}

ABA. Documentos do Grupo de Trabalho sobre as comunidades Negras Rurais .IN: Boletim Informativo NUER, nº 1, 1994.

ALMEIDA, A.W.B. Terras de quilombo, terras indígenas, "babaçuais livres", "castanhais do povo", faxinais e fundos de pasto: terras tradicionalmente ocupadas. Projeto Nova Cartografia Social da Amazônia, PPGSCAUFAM-Fundação Ford, Manaus, 2008. (Coleção Tradição e Ordenamento Jurídico).

ALMEIDA, A.W.B. Nas bordas da política étnica: Os quilombos e as políticas sociais. In: Territórios Quilombolas: Reconhecimento e titulação das terras. Boletim Informativo do NUER - Vol. 02, nำ 02, 2005.

ALMEIDA, A.W.B. Carajás: A guerra dos mapas. Belém, Falangola, 1994.

ALMEIDA, A.W.B. Terras de Preto, Terras de Santo e Terras de Índio- Uso Comum e Conflito. Revista do NAEA. UFPA, 1989.

ANDRADE, M. Quilombolas- etnicidades emergentes? Subsídios para uma discussão. Ciências Humanas em Revista. São Luís, V. 4, no 01, junho 2006.

BENI, M.C. Política e Planejamento Estratégico no Desenvolvimento Sustentável do Turismo. Turismo em Análise, v.17, n.1, p-5-22, maio 2006.

BRASIL. Política Nacional de desenvolvimento Sustentável para povos e comunidades tradicionais. Decreto Presidencial 6.040/2007 de 07 de fevereiro de $2007 . \quad$ Disponível em <http://www.planalto.gov.br/ccivil 03/ Ato2007-2010/2007/Decreto> 
BUARQUE, S. C. Metodologia de planejamento do desenvolvimento local e municipal sustentável. Projeto de Cooperação Técnica INCRA/IICA PCT - INCRA/IICA. Material para orientação técnica e treinamento de multiplicadores e técnicos em planejamento local e municipal, Brasília, $1994 . \quad$ Disponível em $<$ http://www.iica.org.br/Docs/Publicacoes/Publicacoes/lCA/SergioBuarque.p df>. Acesso em: 29 maio 2011.

BURSZTYN, I.; BARTHOLO, R.; DELAMARO, M. Turismo pra quem? Sobre caminhos de desenvolvimento e alternativas para o turismo no Brasil. In: BARTHOLO, R.; SANSOLO, D.G.; BURSZTYN, I. Turismo de base comunitária: diversidade de olhares. 144-162. Brasília, Letra e Imagem, 2009. P. 76- 107.

CORIOLANO, L.N.M.T O turismo comunitário no nordeste brasileiro. In: BARTHOLO, R.; SANSOLO, D. G.; BURSZTYN, I. Turismo de base comunitária: diversidade de olhares. 144-162. Brasília, Letra e Imagem, 2009. P.277-287.

FABIANI, A. Mato Palhoça e Pilão. São Paulo: Expressão Popular, 2005. IRVING, M.A. Ecoturismo em áreas protegidas: da natureza ao fenômeno social. In: NEIMAN, Z.; COSTA, N.M.C.; COSTA, V.C. ( orgs.). Pelas trilhas do Ecoturismo. São Carlos: editora Rima, 2008, p. 1-15.

LEITE, I.B. (org.). Os quilombos no Brasil: Questões Conceituais e Normativas. Cadernos Textos e Debates NUER, Porto Alegre, n.7, p.14, 2000.

HAVERI, A. Strategy of comparative advantage in local communities, 1996. Disponível em: <www.uta.fi $>$. Acesso em: 28 jul. 2009.

KRIPPENDORF, J. Sociologia do Turismo: para uma nova compreensão do lazer e das viagens. São Paulo: Aleph, 2000.

NAVARRO, L. Levantamento da UnB identifica 2.228 territórios quilombolas no Brasil, mas apenas 70 são reconhecidos pelo governo. Universidade de Brasília, maio, 2005. Disponível em: <www.unb.br/acs/unbagencia/ag0505>. Acesso em: 11 de outubro de 2007.

PROJETO VIDA DE NEGRO. Vida de negro no Maranhão: uma experiência de luta, organização e resistência nos territórios quilombolas. São Luís: SMDC/CCN-MA/PVN, 2005.

REIS, J.J. Quilombos e revoltas escravas no Brasil. Revista USP, São Paulo, n.28, p. 14-39, dez. 1996

TRIGO, L.G.G. A sociedade pós-industrial e o profissional em turismo. 5 ed. Campinas: Papirus, 1998.

TUCUM. Rede Cearense de Turismo Comunitário. Presentation held at the II International Seminar on Sustainable Tourism. Fortaleza, 2008.

TURISOL. Rede Brasileira de Turismo Comunitário e Solidário. Presentation held at the II International Seminar on Sustainable Tourism. Fortaleza, 2008.

WWF-INTERNACIONAL, julho 2001. Directrices para el desarollo del turismo comunitário. Disponível em $<$ http://www.panda.org/resources/publications/sustainability/indigenous/Guid elines sp.pdf.Acessp> em 08 /dez/2004. 
ZAOUAL, H. Nova economia das iniciativas locais: uma introdução ao pensamento pós-global. Rio de Janeiro: DP\&A; COPPE-UFRJ, 2006.

\section{Entrevistas:}

BELFORT, Bernardino. Entrevista sobre a história de Filipa. Entrevista concedida em 19 de fevereiro de 2009.

BELFORT, Miguel. Entrevista sobre a história de Filipa. Entrevista concedida em 19 de fevereiro de 2009.

FERREIRA, José Xavier. Entrevista sobre a história de Filipa. Entrevista concedida em 19 de fevereiro, 02 de março e 18 de junho de 2009.

FERREIRA, Minervina. Entrevista sobre a história de Filipa. Entrevista concedida em 19 de fevereiro de 2009.

SANTOS, Ferreira Guiomar. Entrevista sobre a história de Filipa. Entrevista concedida em 19 de fevereiro de 2009.

SANTOS, Donata Vieira da Silva dos. Entrevista sobre a história de Filipa. Entrevista concedida em 17 de abril de 2009.

SANTOS, Lindalva. Entrevista sobre a história de Filipa. Entrevista concedida em 19 de fevereiro de 2009.

SANTOS, Raimundo Oliveira. Entrevista sobre a história de Filipa. Entrevista concedida em 19 de fevereiro de 2004 e 02 de março de 2009.

VIANNA, Nielza Ferreira. Entrevista sobre a história de Filipa. Entrevista concedida em 19 de fevereiro, 02 de março e 18 de junho de 2009.

\section{Notas:}

${ }^{1}$ Michel Hatton. "The character of community-based tourism" disponível em http://www.community-tourism.org/ (acessado em 16 de julho de 2007)

${ }^{2}$ Rede Brasileira de Turismo Comunitário e Solidário.

${ }^{3}$ Rede Cearense de Turismo Comunitário.

${ }^{4}$ Entrevista realizada com Sra. Donata Vieira da Silva dos Santos, em 17 de abril de 2009.

Rosijane Evangelista da Silva: Universidade Estadual de Santa Cruz, Ilhéus, BA, Brasil.

E-mail: fedele.e@hotmail.com

Link para o currículo Lattes: http://lattes.cnpq.br/9046617515633941

Data de submissão: 29 de junho de 2012

Data de recebimento de correções: 17 de julho de 2013

Data do aceite: 19 de fevereiro de 2014

Avaliado anonimamente 


\section{APÊNDICES}

\section{Apêndice A - Roteiros de entrevistas}

Universidade Estadual de Santa Cruz - UESC

Mestrado Acadêmico em Cultura e Turismo

Pesquisa: Turismo de base comunitária: alternativa para o etnodesenvolvimento da comunidade quilombola de Filipa - MA.

Mestranda: Rosijane Evangelista da Silva

Orientadora: Moema Badaró Midlej

Roteiros Orientativos para Entrevistas Semi-Estruturadas na comunidade

Roteiro I

1. De onde nasceu a comunidade de Filipa?

2. Há quanto tempo vocês vivem assim?

3. O que é ser quilombola?

4. Como é a relação de vocês com a natureza?

5. E com a terra?

6. Sempre foi assim?

Roteiro II

1. E a produção, como é?

2. O que vocês produzem?

3. Como é a organização em Filipa? Como vocês se organizam?

4. É importante se organizar? Por quê?

5. Como é, para você, participar da Associação de Moradores?

6. A sua opinião é importante para a comunidade?

Roteiro III

1. E turismo? O que você pensa sobre turismo?

2. Para você, o que é turismo?

3. Existe turismo aqui em Filipa? Como acontece?

4. A comunidade já conversou sobre o turismo? Quando? O que vocês concluíram?

5. O que você acha que o turismo pode trazer para Filipa?

6. O que a comunidade pode oferecer ao visitante?

7. O que espera receber do turista?

Roteiro IV

1. E as mulheres, que papel elas representam para a comunidade?

2. E os jovens? Como se encaixam na comunidade? São Importantes?

3. Eles (os jovens) também falam e são ouvidos por vocês?

4. Participam e influem nas decisões sobre o coletivo?

5. Como é a cultura Quilombola de Filipa?

6. Quais as festas e manifestações importantes?

7. Os mais jovens gostam de participar?

8. Como é cultivada, nas crianças, a trajetória e a cultura da comunidade? 


\section{Apêndice B - Relação das pessoas entrevistadas na comunidade de Filipa - MA}

\section{ENTREVISTAS:}

Ana Ferreira: agricultora, 85 anos, coureira de tambor de crioula, moradora de Filipa.

Bernardino Ferreira Belfort: agricultor, 81 anos, bisneto de Filipa, morador da comunidade.

Cristiane Araujo Ferreira: 19 anos, descendente de Filipa e membro da comunidade.

Donata Vieira da Silva dos Santos: agricultora, 56 anos, esposa do Sr. Bernardino, atual presidente da Associação São Sebastião dos Produtores do Quilombo de Filipa.

Guiomar Ferreira dos Santos: agricultora, 36 anos, membro da diretoria da Aconeruc.

Hilton dos Santos Ferreira: 78 anos, agricultor, bisneto de Filipa, membro da comunidade.

José Xavier Ferreira: agricultor, 46 anos, descendente de Filipa, morador da comunidade.

Lindalva Araujo dos Santos: 38 anos descendente de Filipa, dona de casa e líder comunitária, esposa do Sr. Raimundo.

Marcelo Ferreira dos Santos: 23 anos, presidente da Associação dos Jovens Produtores de Filipa.

Maria de Lourdes Santos Ferreira: agricultora, 37 anos, moradora da comunidade.

Miguel Ferreira Belfort: agricultor, 82 anos, bisneto de Filipa, morador da comunidade.

Minervina dos Santos Ferreira: aposentada, 87 anos, bisneta de Filipa, coureira de tambor de crioula, membro mais idosa da comunidade.

Nielza Ferreira dos Santos: bisneta de Filipa, 74 anos, agricultora, professora e líder da comunidade.

Raimundo Nonato Gomes Bezerra: agricultor, 42 anos, presidente do Sindicato dos Trabalhadores Rurais do Município de Itapecuru-Mirim. 